\section{Vocation, Autonomy, Agency, and Meaning}

\section{TO THE EDITOR:}

Dr Stephen A. Wilson wrote an elegant essay on burnout in the July-August edition of Family Medicine. His insight regarding physician loss of agency and autonomy and our own complicity with factors that contribute to this loss (ie swapping autonomy for less call, stable salary, and benefits) is compelling.

In looking for security and giving up control, we may also be giving up or allowing an erosion of the notion of medicine as a vocation. We may be giving up the respect and authority imbued in the essence of the healing profession as a calling.

We teach people how to treat us by our own actions.

I heard a highly placed nonclinician state, "We just need more technicians." If we believe that statement, if we allow ourselves to be treated, as Wilson describes, as "highly skilled assembly line workers" replaceable by a technician or interchangeable with each other, then we have a diminished sense of influence.

Now more than ever, we need to have influence. In our profession we take an oath, we hold sacred the healing value of trust built between a patient and a physician. In the slow ebbing away of that once-cherished relationship we lose our sense of purpose and meaning.

In our hierarchical employment relationships, we may lose both authority and leadership ability within our care teams.
Returning to the concept of our profession as a vocation does not imply a return to the unsustainable, imbalanced hours of physicians of yesterday, whose work negatively impacted their own health and the health of their families. Work-life imbalance is another source of burnout.

Physician burnout impacts not only the physician, but also patients and communities as Wilson notes.

Wilson proposes a union of physicians to provide a stronger voice to reclaim our agency and autonomy. He writes: "A virtuous physicians union - the only type worth considering - would have patients and patient outcomes as the primary foci."

Whether in a union or not, fundamentally, we must recommit to our profession as a vocation. We must recommit to its principles and the healing value of our physician-patient relationships. We must teach and model selfrespect for our students and demand it of our organizational leaders. We must cherish anew what we each uniquely bring to the art and science of our profession.

In doing so, we may rediscover the agency, autonomy, and meaning that we have lost.

Maureen A. Mavrinac, MD

Los Angeles, CA

doi: 10.22454/FamMed.2018.646725

\section{References}

1. Wilson SA. Burnout: Lewin's heuristic, athletes' preparation, and unionization. Fam Med. 2017;49(7):571-573. 